\title{
Extending a physiological forest growth model by an observation- based tree competition module improves spatial representation of diameter growth
}

\author{
Werner Poschenrieder • Rüdiger Grote • \\ Hans Pretzsch
}

Received: 30 October 2012/Revised: 7 June 2013/Accepted: 9 August 2013/Published online: 22 August 2013

(C) The Author(s) 2013. This article is published with open access at Springerlink.com

\begin{abstract}
One of the pivotal objectives in forestry research is to estimate the response of silvicultural target variables to climate change scenarios at high temporal resolution in order to consider within-year feedbacks between growth and environmental conditions. To meet this challenge, models are needed which support and complement the widely used observation-based decision systems in forest management and consulting. Physiological models in particular provide the fundamental prerequisites to reflect the impact of various simultaneously changing environmental conditions. However, a physiological representation at the individual tree level is computationally very expensive and sensitive to uncertain initializations. We thus propose an approach that combines a modern representative of the physiological cohort model type, MoBiLE-PSIM, with the individual tree competition concept of a distance-dependent empirical growth simulator (SILVA). The resulting hybrid provides a key feature for the consideration of forest management in long-term simulations at high computational efficiency. The extended model was evaluated with growth-diameter distributions
\end{abstract}

Communicated by A. Weiskittel.

Electronic supplementary material The online version of this article (doi:10.1007/s10342-013-0730-1) contains supplementary material, which is available to authorized users.

W. Poschenrieder $\cdot$ H. Pretzsch

Chair of Forest Yield Science, Technische Universität München,

Hans-Carl-von-Carlowitz-Platz 2, 85354 Freising, Germany

R. Grote $(\bowtie)$

Institute for Meteorology and Climate Research (IMK-IFU),

Karlsruhe Institute of Technology (KIT), Kreuzeckbahnstr. 19,

82467 Garmisch-Partenkirchen, Germany

e-mail: Ruediger.Grote@kit.edu obtained from core-boring at two beech (Fagus sylvatica $L$.) forest sites in south-west Germany that differ in exposure and soil conditions. The mean bias of annual standscale growth from 2001 to 2007 decreased from -0.59 to $-0.41 \mathrm{~mm}$ at one evaluation plot and from -0.55 to $0.24 \mathrm{~mm}$ at the other when the competition module was coupled in. Inclusion of the SILVA-based individual tree module into MoBiLE-PSIM improved the size-dependent representation of competition and growth on five-year and even annual timescale. This was particularly the case where the spatial distribution of dominant trees was clustered.

Keywords Cohort model - Physiological model . Individual tree growth - European beech $\cdot$ MoBiLE . SILVA

\section{Introduction}

Simulation models play an increasingly important role as supporting instruments for the decision maker in his task to provide multifunctional sustainability (Muys et al. 2010). The most common type of model in practice is the observation-based individual tree management model (Pretzsch et al. 2008). It is based on the long-term monitoring of experimental sites and provides for a reliable estimation of future stock, growth, yield or even structure and diversity under the environmental conditions of observation. Real forest systems of today are exposed to climatic change (Saxe et al. 2002; Boisvenue and Running 2006) in combination with an increase in soil nitrogen and atmospheric $\mathrm{CO}_{2}$ accompanied by prevalent atmospheric intoxication (Ollinger et al. 2002) at least in the strongly industrialized part of the world. Additionally, the inter-annual and intra- 
annual variability of weather will be different in future. As a further source of uncertainty, all environmental factors are interacting via plant internal processes (Löw et al. 2006; Matyssek et al. 2006), and their synergetic impact is strongly influenced by the changing inter-annual variation of weather (Kubiske et al. 2006). Hence, the observed relation between integrated climate variables and growth (Porte' and Bartelink 2002) is likely to change. Thus, there is a demand for models that reflect the influence of various climatic driving forces and chemical boundary conditions in yet unobserved combination.

As a basic prerequisite, they must take into account all physiological processes which are individually affected by environmental impacts and all relevant positive and negative feedbacks among them (Landsberg 2003). On a higher level of causality, this is also true for long-term effects of structural changes in the vicinity of a tree, e.g. from an increase in light supply to a decrease in leaf area index (e.g. Portsmuth and Niinemets 2007). Structure and structural development must also be considered on the stand level (e.g. Langvall and Löfvenius 2002) to estimate how the impact of long-term changes might be mitigated or best capitalized (Goreaud et al. 2006). In individual tree, physiological models such as BALANCE (Grote and Pretzsch 2002; Rötzer et al. 2005) modellers have merged available theory about the underlying processes of growth into mechanistic aggregates of soil and vegetation modules that take into account individual tree position, dimension and vertical crown stratification. In contrast to the typical process model which is mechanistic and detailed for processes that are relevant to a selected focus (as reviewed by Mäkelä et al. 2000), such as carbon fixation, the ecopyhsiological individual tree model is designed to estimate the distribution of tree dimensional growth with a very high generality. It provides a high spatial differentiation of processes and runs in subdaily to daily time steps, and it is very sensitive to uncertainties in individual initialization (Fontes et al. 2010), costly in parameterization and comparatively slow. To reduce complexity while preserving a high degree of mechanistic description, Grote et al. (2011b) have represented stand structure in MoBiLE-PSIM as an ensemble of spatially interacting single species cohorts, where each cohort consists of trees that are identical in dimension and are ordered on a regular grid. Presuming this approximation, competition may be covered by exclusively simulating one representative tree per cohort, and computational efficiency is increased by an order of magnitude.

One central criterion of individual tree model evaluation is to meet the interannual variability of the growth to size distribution: following an increasingly well-confirmed theory (Schwinning and Weiner 1998; Weiner 1990; Wichmann 2001, 2002; Pretzsch and Biber 2010; Pretzsch and Dieler 2011), a concentration of growth on either larger or smaller trees reflects the coupling of aboveground and belowground competition. If belowground resource supply is not limiting, tree dominance is characterized by shading (asymmetric competition) and the regression line between diameter growth and diameter has a steep slope and an intersect with the DBH axis at the right side of the origin. With decreasing soil resource availability, the slope inclines around some point near the centre of the distribution towards the horizontal. A cohort model which accounts for size-specific resource limitations could principally reflect this response, but the relationship between growth and diameter would only be represented by one single point per cohort. Hence, the distributional width has to be recreated with a semi-empirical individual tree algorithm, if the simplicity which is gained by the cohort approach is to be preserved.

Within the scope of this article, we present the extension of the ecophysiological cohort model MoBiLE-PSIM (short MoBiLE) by an individual tree growth interpolation that is based on the semi-empirical competition algorithm used in the growth simulator SILVA (Pretzsch et al. 2002) but is set up in order to satisfy the simulated cohort volume increase. Both MoBiLE and the interpolation plug-in are coupled in both directions on the annual timescale: the controlling variable provided by MoBilE is the cohort volume growth, and the ones returned back are the new dimensions of the cohort representative tree. Our method is innovative as compared to earlier approaches of model coupling (Baldwin et al. 2001; Milner et al. 2003; Henning and Burk 2004) because it combines many of their different benefits, (a) extends them by most recent physiological concepts, (b) implies a bidirectional control between individual growth and stand development on a timescale of one year, which is also sensitive to management actions and (c) uses a mass conservative algorithm to calculate individual tree dimensional growth from cohort total stem biomass increase: the approach is related to the work of Weiskittel et al. (2010), Kirschbaum (1999) and Korol et al. (1996) in that it aims to scale the biomass increment simulated by a stand-level physiological model down to the individual tree level. However, it is different in that it uses an individual tree growth prediction by a distance-dependent empirical model as the weighting criterion.

Within the context of European forestry, one important application of our hybrid model will be sensitivity assessment of European beech (Fagus sylvatica L.) to future environmental conditions: beech is supposed to be very competitive under a wide range of conditions (Bolte et al. 2007, 2010) but has been replaced by spruce and other coniferous species that are thought to be less adapted to expected environmental conditions in many regions (Koca et al. 2006; Bolte et al. 2010). As comprehensively 
explained by Brumme and Khanna (2009), its increased cultivation in central Europe is heavily advocated to preserve and enhance biodiversity in a changing climate and to provide long-term sustainability of forests and the productivity of forest stands. In this situation, some concern has been expressed about the relatively small knowledge base about the response of European beech to drought conditions (Jump et al. 2006; Geßler et al. 2007; Friedrichs et al. 2009). Our model evaluation takes advantage of extensive data from two areas in south-west Germany that have repeatedly been investigated for forestry and ecophysiological purposes (e.g. Geßler et al. 2001; Holst et al. 2010). They are situated within a region of shallow soils on porous limestone where growth depressions due to drought have repeatedly affected stand development in the past (Maaten 2011).

\section{Materials and methods}

\section{Site description}

The experimental sites are located in south-western Germany near Tuttlingen, about $100 \mathrm{~km}$ east of the city of Freiburg $\left(47^{\circ} 59^{\prime} \mathrm{N}, 8^{\circ} 45^{\prime} \mathrm{E}\right)$ at about $800 \mathrm{~m}$ a.s.l. They have repeatedly been described elsewhere in more detail (e.g. Geßler et al. 2001; Mayer et al. 2002). One slope is facing towards SW direction (defined as SW slope), while the aspect of the second slope is NE (NE slope). The horizontal distance between both sites (control plots) is about $800 \mathrm{~m}$. Both hillsides are covered with 80-90-year-old single-layer, beech-dominated ( $>90 \%$ ) forest stands. A summary of general site properties and stand characteristics is presented in Table 1, and the situation is shown in Fig. 1 (taken from Holst et al. 2004a, b, 2010; Paul 2003; photosynthetically active radiation PAR from Mayer et al. 2002).

According to the site description by Geßler et al. (2005), soil profiles are characterized as Rendzic Leptosols derived from limestone (Weißjura beta and gamma series). On both slopes, the soil profiles are shallow, averaging less than $50 \mathrm{~cm}$ depth of topsoil before becoming dominated by parent rock interspersed with pockets of organic matter and mineral soil. The soil profile on the SW slope is particularly rocky, containing more than $40 \%$ (volumetric basis) rocks and stones ( $>63 \mathrm{~mm}$ diameter) in the top $20 \mathrm{~cm}$ of the soil, rising to $80 \%$ below $50 \mathrm{~cm}$ depth. The soil on the NE slope contains $15 \%$ rocks and stones in the uppermost $20 \mathrm{~cm}$ of the soil and about $30 \%$ below $50 \mathrm{~cm}$ depth.

Two control plots NE-C $(68 \mathrm{~m} \times 77 \mathrm{~m}$ at horizontal projection) and $\mathrm{SW}-\mathrm{C}(71 \mathrm{~m} \times 70 \mathrm{~m})$ were selected for evaluation, which had not been thinned after setup of the experimental site in early 1999. Mean stand properties based on a forest inventory in Winter 1998/99 are given in Table 2 (height and diameter have been taken from Hauser (2003), and the number of trees per ha at horizontal projection has been calculated based on the tree lists).

Although the stand at site NE is about 10 years younger, its mean basal area stem is higher and has a larger diameter. Even if NE-C has a wider range of variation in $\mathrm{DBH}$ than SW-C, both plots have a bell-shaped DBH distribution that indicates an even-aged structure. Number of trees by $\mathrm{DBH}$ (diameter at breast height) interval and height over

Table 1 Experimental site properties (numbers in italics are estimates based on soil type)

\begin{tabular}{|c|c|c|c|c|c|c|}
\hline Site property & \multicolumn{3}{|l|}{$\mathrm{NE}$} & \multicolumn{3}{|l|}{ SW } \\
\hline Elevation (m a.s.1.) & \multicolumn{3}{|l|}{820} & \multicolumn{3}{|l|}{760} \\
\hline Slope (degree) & \multicolumn{3}{|l|}{23} & \multicolumn{3}{|l|}{25} \\
\hline Annual mean temperature, $2001-2007\left({ }^{\circ} \mathrm{C}\right)$ & \multicolumn{3}{|l|}{7.4} & \multicolumn{3}{|l|}{7.5} \\
\hline Annual average precipitation, 2001-2007 (mm) & \multicolumn{3}{|l|}{906} & \multicolumn{3}{|c|}{1,064} \\
\hline PAR at 1.3-fold stand height in $2001\left(\mu \mathrm{mol} \mathrm{m}{ }^{-2} \mathrm{~s}^{-1}\right)$ & \multicolumn{3}{|l|}{243} & \multicolumn{3}{|l|}{245} \\
\hline Soil type & \multicolumn{3}{|c|}{ Silty clay loam } & \multicolumn{3}{|c|}{ Silty clay loam } \\
\hline Humus type & \multicolumn{3}{|l|}{ Mull } & \multicolumn{3}{|l|}{ Mull } \\
\hline Litter height (mm) & \multicolumn{3}{|l|}{90} & \multicolumn{3}{|l|}{80} \\
\hline Specific soil parameters in depth of $(\mathrm{cm})$ : & 10 & 30 & $\mathbf{5 0}$ & 10 & 30 & 50 \\
\hline Depth of the soil profile $(\mathrm{mm})$ & 190 & 160 & 200 & 190 & 160 & 100 \\
\hline Stone fraction $(0-1)$ & 0.21 & 0.20 & 0.30 & 0.52 & 0.35 & 0.35 \\
\hline Soil bulk density $\left(\mathrm{kg} \mathrm{dm}^{-3}\right)$ & 0.74 & 1.73 & 1.85 & 0.59 & 1.73 & 1.85 \\
\hline Clay content $(0-1)$ & 0.45 & 0.49 & 0.49 & 0.46 & 0.49 & 0.49 \\
\hline Water holding capacity $\left(\mathrm{mm} \mathrm{m}^{-1}\right)$ & 500 & 500 & 500 & 500 & 500 & 500 \\
\hline Water content at wilting point $\left(\mathrm{mm} \mathrm{m}^{-1}\right)$ & 270 & 75 & 270 & 170 & 75 & 270 \\
\hline
\end{tabular}

The bold values indicate on the one hand the information about the soil depth investigated, on the other hand they also representthe heading for the depth-specific information in the following rows 

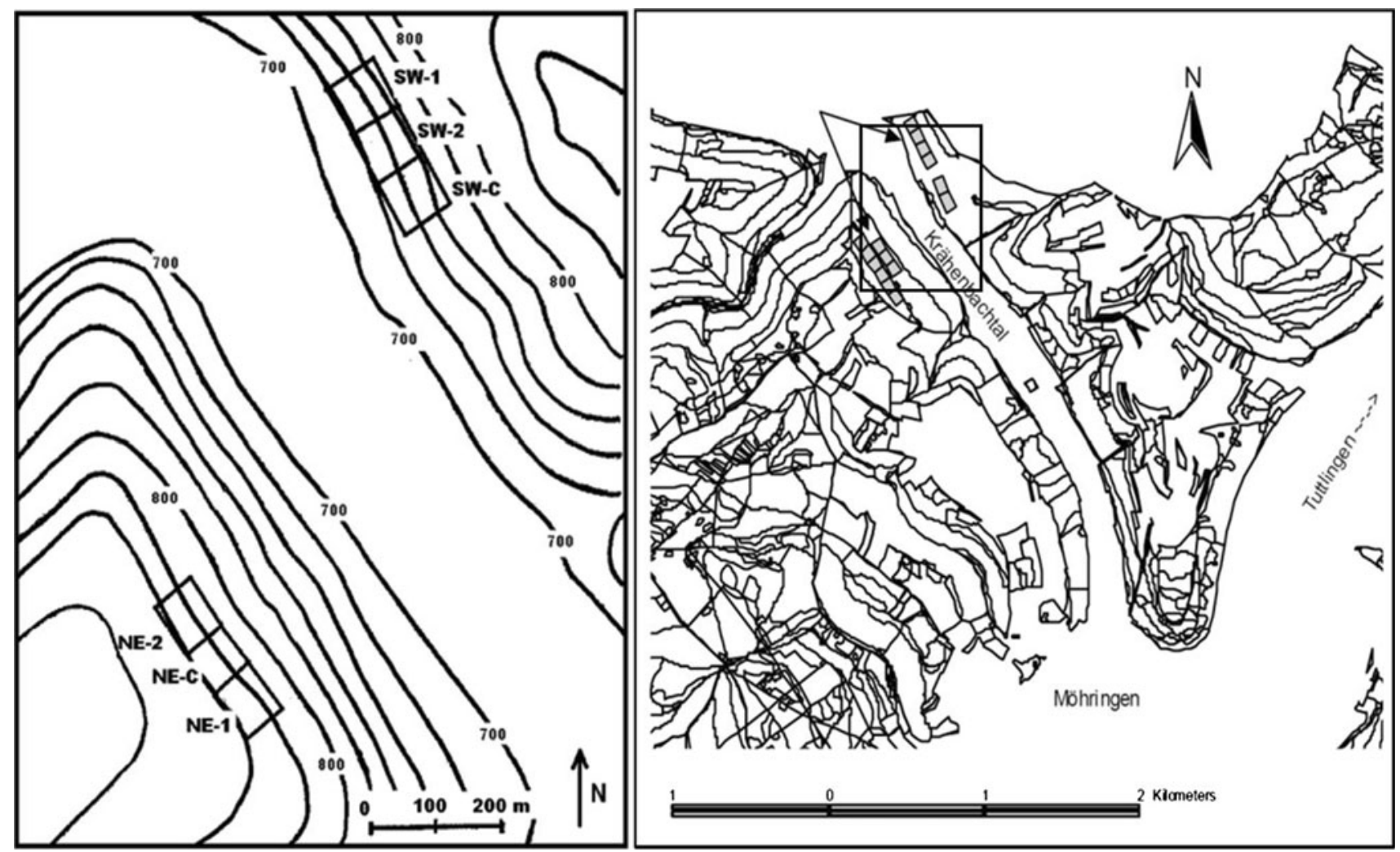

Fig. 1 Position of the two experimental sites and three trials at each location. Only control trials (SW-C and NE-C) are used in this investigation, and other trials represent different thinning intensities. (Figures reproduced from Holst et al. 2004a; Paul 2003)

Table 2 Growth- and yield-related key properties by plot

\begin{tabular}{lll}
\hline Plot property & NE-C & SW-C \\
\hline Mean basal area stem & & \\
Height $(\mathrm{m})$ & 26.5 & 21.1 \\
Diameter at $1.3 \mathrm{~m}(\mathrm{~cm})$ & 25.6 & 21.5 \\
Diameter $95 \%$ range of variation $(\mathrm{cm})$ & $10-39$ & $11-32$ \\
Number of trees per ha & 516 & 658 \\
\hline
\end{tabular}

DBH as determined from a stand height curve by the growth simulator SILVA (Pretzsch et al. 2002) are shown in Fig. 2a, b. Figure 3 is a map of stem base position and DBH: at NE-C, it has a rather irregular pattern, whereas at SW-C it shows a clear concentration of larger trees at the centre of the downhill side. The species distribution within each of the two plots included $94 \%$ beech and minor contribution of other hardwood. All trees were thus considered as beech in the simulations and following analysis.

Measurements

Individual tree data within our study were DBH and position that had been taken in winter 1998/99 (Hauser 2003) and borer probes taken in early spring 2011. Based on the age-corrected DBH distribution of 1999 and on the observed frequency of DBH within intervals of $10 \mathrm{~cm}$, a stratified sample of each plot was taken in March 2011 $(n=27$ at NE-C, $n=26$ at SW-C, Fig. 2c). From each sample tree, two stemwood cores were taken at breast height with an angular distance of $90^{\circ}$ from each other, and one of the cores was taken on the uphill side. At NE-C, both cores of 23 trees were used for evaluation while in the remaining four cases, only one core per tree could be used due to damage of the second probe. At SW-C, all probes were suitable for analyses. Tree height, height to crown base and crown diameter were computed by the growth simulator SILVA (Pretzsch et al. 2002), based on the individual tree lists and the mean basal area stem height.

\section{Model description}

The physiological part of the hybrid model is represented by the modelling framework MoBiLE (Modular Biosphere simuLation Environment; Grote et al. 2009; Holst et al. 2010) in a configuration that uses the physiologically based vegetation module PSIM (Physiological SImulation Model, Grote 2007; Grote et al. 2009) and a newly implemented version of the biogeochemical module DNDC (DeNitrification-DeComposition, Li et al. 1992) along with modules that describe micro-environmental conditions within the 

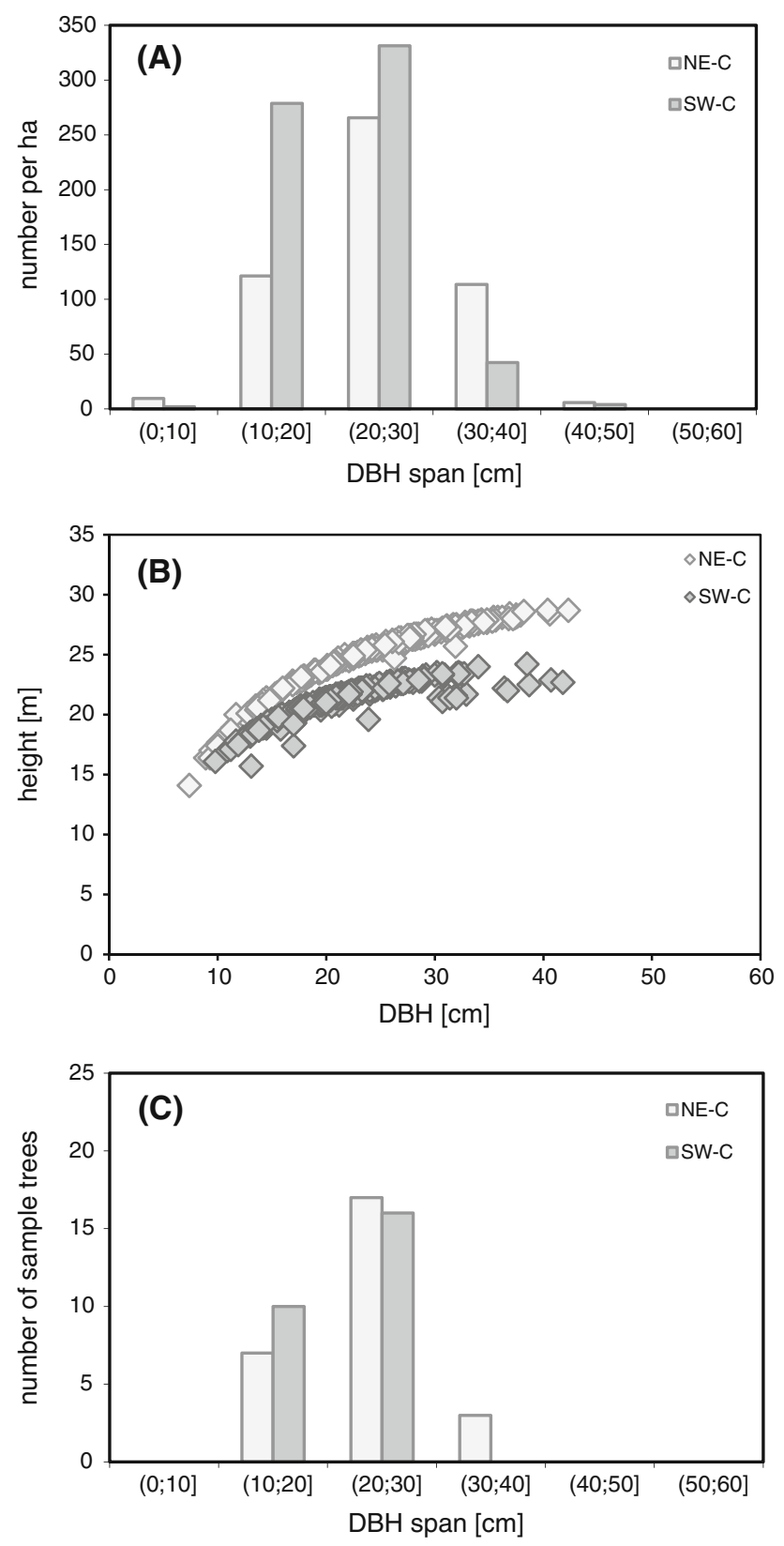

Fig. 2 Stand structure indicated as a number of trees per ha by DBH interval and b height by $\mathrm{DBH}$, as compared to $\mathbf{c}$ frequency distribution by coring subsample, given as the number of trees used for subsampling

biosphere (e.g. light distribution, soil temperature development and water availability). It is represented by the left part of Fig. 4 and commonly named MoBiLE-PSIM (short MoBiLE).

MoBiLE runs in a subdaily (hourly) time step with respect to the photosynthetic equations and in a daily time step for other processes. Photosynthesis is computed according to Farquhar et al. (1980) with modifications suggested by Ball et al. (1987). The PSIM module simulates uptake, loss and allocation of $\mathrm{C}$ and $\mathrm{N}$ within the plant as determined by sink strength (Grote 1998; Grote et al. 2011a) that is based on allometric rules. It runs on a daily time step. PSIM considers the ecosystem to be consisting of 'vegetation types' or 'cohorts' of distinct species, vertical dimension and ground coverage. Each cohort is represented by its average tree characterized by diameter, height, height at crown base and stem number: a separate vegetation structure module converts the carbon gain of the cohort given by PSIM to the corresponding total stem volume increase at annual time step. It then uses a taper function to convert the average stem volume increase to the dimension growth of the representative tree as described in Grote et al. (2011a, b). The new representative tree dimensions define the new structural features that influence leaf distribution and thus radiation regime and competition within the canopy in the following year.

If a detailed tree list is used as input, the average cohort tree at simulation start is calculated from this list, using tree height and crown base height as selection criteria for a cohort. All trees within a cohort are thus considered equal and are assumed to be arranged in a homogeneous pattern that also might allow for a certain amount of gaps, provided the ground coverage-as calculated from diameter and crown diameter ratio-is below $100 \%$ (see Grote et al. 2011a for further information). Stem volume and consequent biomasses are calculated from species-specific taper functions and allometric relationships.

PSIM differentiates canopy and soil into a number of vertical layers with a thickness of about $50 \mathrm{~cm}$ aboveground and-depending on initialization-10-50 cm belowground. The environmental conditions experienced by a cohort in MoBiLE are defined by the resources available within the above- and belowground layers that it occupies according to its height, height at crown base and rooting depth. Foliage area and fine root biomass are explicitly distributed in vertical direction at the spatial resolution of the layering. Several cohorts may occupy the same layer. Hence, a tree cohort affects its own environment and that of other cohorts by shading and uptake (nitrogen, water) on the level of canopy and soil layers. On the stand level, it may thus exert aboveground competition on other cohorts that concentrate their foliage in canopy layers further down. Belowground, the competition strength of a cohort depends on the presence of fine roots in a particular soil layer and the species-specific uptake capacity. As maximum rooting depth for mature beech trees is considered to be approximately $3 \mathrm{~m}$ in the model, all cohorts are assumed to have access to the whole soil profile. Despite the differentiation into cohorts and the consideration of a certain gap fraction, all processes are simulated as 'one-dimensional', and thus, the emerging forest is still horizontally homogeneous-implicitly assuming a uniform distribution of trees within a cohort. 

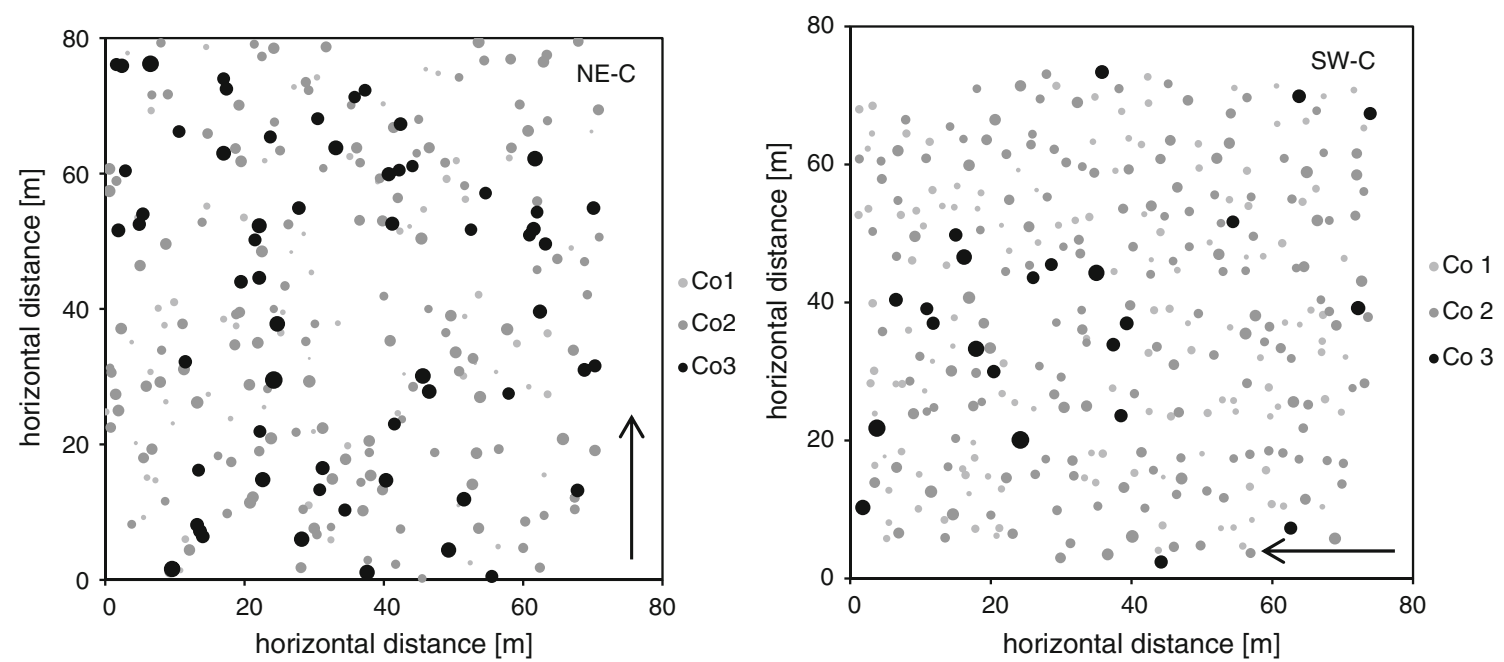

Fig. 3 Stem base positions at site NE-C and SW-C, differentiated by diameter interval (in cm, end diameter excluded) 0-20, 20-30, 30- $\infty$, designated by $\mathrm{Co} 1, \mathrm{Co} 2$ and $\mathrm{Co} 3$, respectively; arrows designate the direct down-slope direction

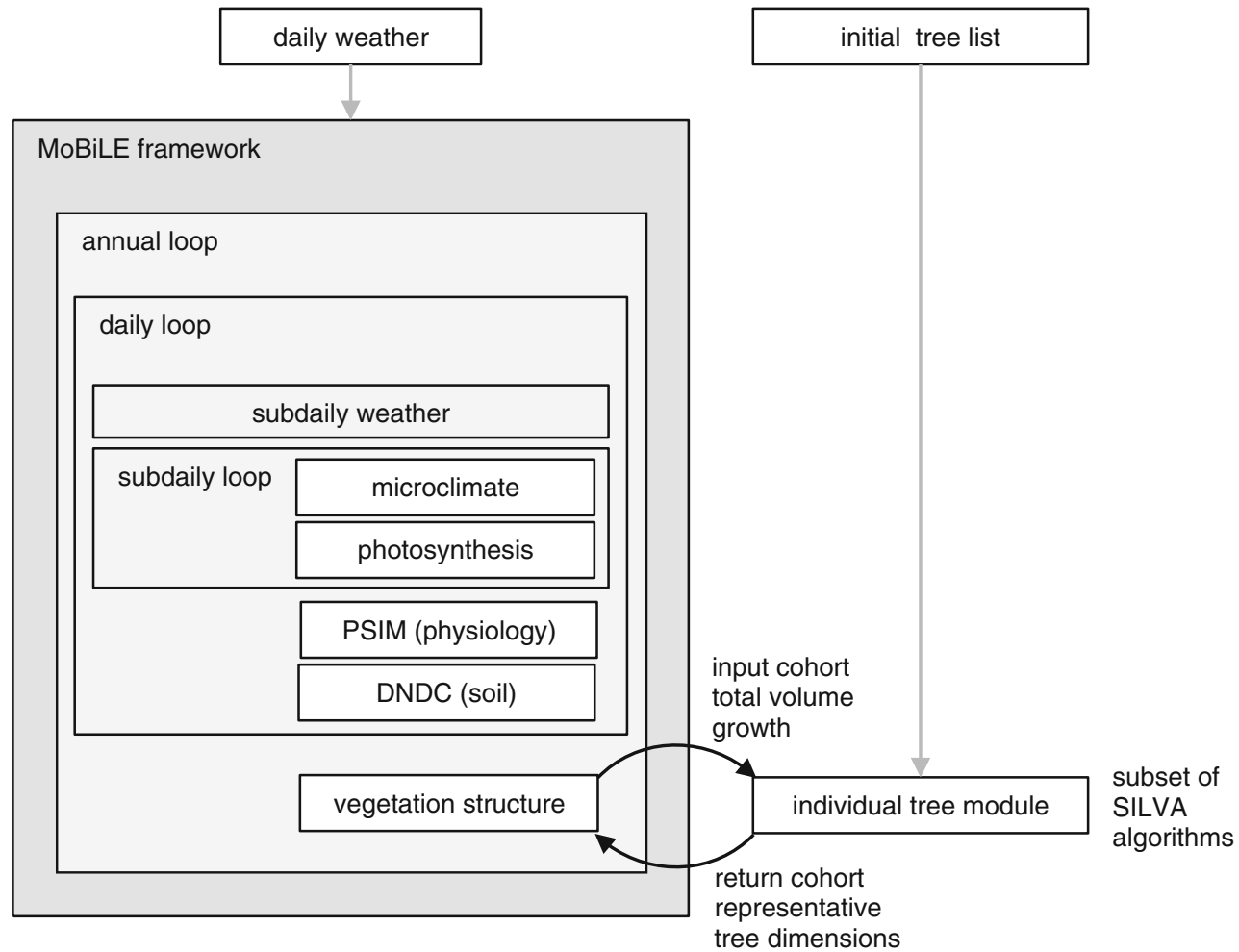

Fig. 4 Integration of the individual tree module into the MoBiLE framework as configured and extended within the scope of this study; the MoBiLE framework part is distinguished from the modules by a grey background

MoBiLE uses a ground basal area weighting to aggregate the cohort representative tree dimensions to the stand level.

The ability of the model to simulate the micro-meteorological conditions and the water balance at the selected sites has been evaluated in an earlier publication (Holst et al. 2010). Species-specific parameters to describe physiological processes, i.e. carbon exchange and biomass allocation, have been determined from literature sources and were evaluated using beech trials at other investigation sites (Grote et al. 2011a). The setup of a cohort simulation and an application for a mixed stand dominated by Scots pine have been presented in Grote et al. (2011b).

To complement MoBiLE with a fast individual tree component, an additional module was embedded into the framework that is based on potential dimension growth and competition equations taken from the individual tree model 
SILVA (Pretzsch et al. 2002). SILVA describes stand development at a level of detail of individual trees and their aboveground dimensions. The model has no physiological or micrometeorological theory of anabolism, catabolism or transport. SILVA models potential growth of an individual tree using the Chapman-Richards equation for height and diameter growth (Richards 1959). The prevailing process within a cohort tree's actual growth is competition, as expressed in the following highly simplified form:

$g=\mathcal{P} \cdot c$

where $g$ is actual growth and $\mathcal{P}$ is the site-specific potential growth for both height and diameter increment. Variable $c$ is the competition-related reduction term that is different for height and diameter growth. It depends on a tree's dimension in relation to the dimension and position of each competing neighbour tree. Hence, total stand density determines each individual tree's growth indirectly via the local density, arrangement and geometry of its competing neighbours: a competitor takes influence only if its tree top reaches into a solid angle (about $60^{\circ}$ ) that opens towards the sky with vertex inside the central tree's crown and position coaxial to the crown vertical axis. The exact value of the virtual cone's angle as well as its position is species specific. If a neighbour reaches into the cone, it exerts competition on the tree depending on the angle between crown base and neighbour tree top, the crown cross-sectional areas and a species-specific light transmission coefficient of the competitor. Furthermore, the resulting competition factor depends on the horizontal distance between the central tree's stem and the centre of gravity of competition. Plot edge effects are corrected by linear expansion based on earlier work of Martin et al. (1977).

Potential growth parameters in SILVA are based on the long-term observation of a high number of plots ranging from northern Germany to Switzerland. They reflect growth as dependent on stand-scale soil and climate conditions. The competition factor equations for height and diameter growth use parameters which are exclusively dependent on species (for more details see Pretzsch et al. 2002). SILVA uses a time step of five years, because its growth curves do not represent the interannual variability of weather, and a higher temporal resolution would not add quality to the simulation result: the curves of potential growth are sigmoid (height) or unimodal (diameter). Potential height at time $t$ is defined as:

$h_{t}=A\left(1-e^{-k t}\right)^{p}$

As SILVA is kept independent of stand age, $t$ is computed from height at the beginning of a simulation interval via the inverse of Eq. 2. In the original model implementation, $A, k$ and $p$ are internal variables that are not given as parameters but calculated from site conditions and species-specific unimodal dose-response functions.

For potential diameter growth, the independent variable is diameter $d$ itself that represents biological age. Diameter increase $\left(\delta_{d}\right)$ is

$\delta_{d}=\alpha \kappa \varphi\left(1-e^{-\kappa d}\right)^{\varphi} e^{-\kappa d}$

where $\alpha, \kappa$ and $\varphi$ are of the same mathematical meaning as $A, k$ and $p$ in Eq. 2 but of distinct value and species-specific. Furthermore to get the actual value of potential growth, the basal area growth that results from Eq. 3 is modified by a climate and nutrient-dependent factor that is named ESto in Pretzsch et al. (2002).

MoBiLE was modified in such way that the vegetation structure module delegates the cohort's representative tree dimension growth to the individual tree module (Fig. 4): the individual tree component offers an interface that takes the cohort volume both at start and end of year and returns the resulting new cohort representative tree dimensions. Therefore, the individual tree component uses an intermediate step that scales down the annual total volume growth of a cohort to an individual volume and dimensional increase in each individual tree (Fig. 5). An individual tree list has to be provided to the individual tree
Fig. 5 Interaction of MoBiLE and the individual tree module simplified

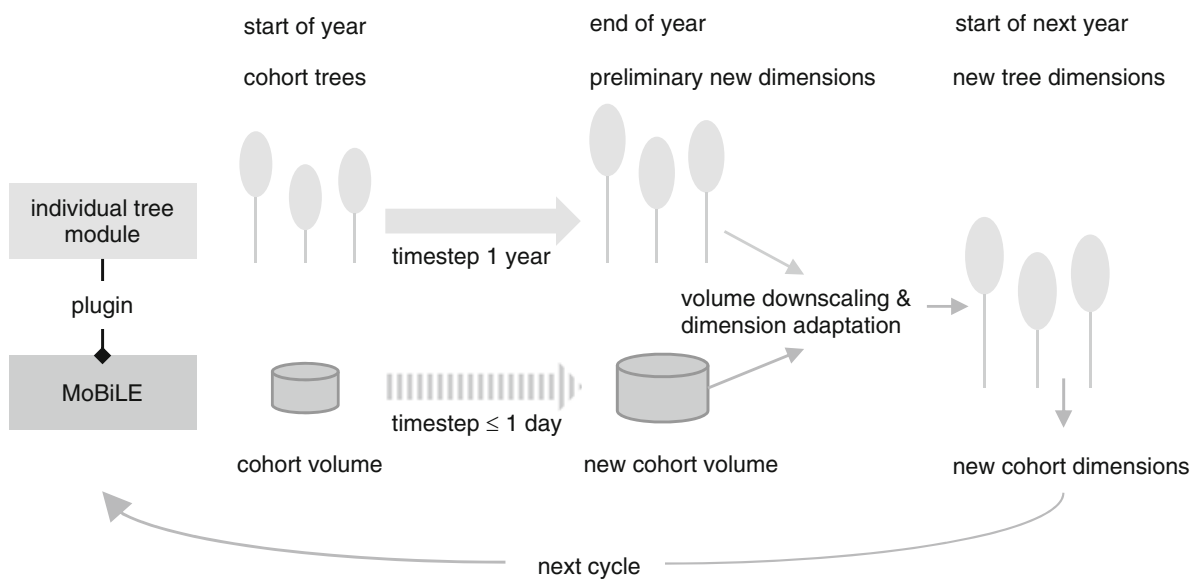


module at simulation start to define starting dimensions for each tree in the stand. The key step of the downscaling algorithm is to compute height and diameter growth of each individual tree at annual time step based on Eqs. 1, 2 and 3 and correct it by the factor shown in Eq. 4 (details are given in the online supplement).

$f=\frac{\sqrt[3]{\omega}-1}{\sqrt[3]{\omega^{*}}-1} \quad$ where $\quad \omega=\frac{v_{1}}{v_{0}} \quad$ and $\quad \omega^{*}=\frac{v_{1}^{*}}{v_{0}^{*}}$

Variables $v_{0}^{*}$ and $v_{1}^{*}$ are individual tree volumes at the start and end of year, respectively: they are calculated from the timber-wood taper function of SILVA. The volume at the end of year $v_{1}^{*}$ results from dimension growth based on Eqs. 1, 2 and 3. Tree volumes $v_{0}$ and $v_{1}$ are calculated from the cohort volumes at start and end of year that are passed to the module and the share respectively of $v_{0}^{*}$ and $v_{1}^{*}$ within the cohort. Intuitively spoken, the expression approximately is the ratio of a dimension change that is in accordance with the physiological part of the hybrid model and one that corresponds to the SILVA growth curves.

To explain the whole concept in a nutshell, the sole task of the physiological part is to calculate the annual carbon gain and volume growth of the cohort representative tree but not the change of its dimensions. The key role of the individual tree module on the other hand is to provide the relative growth of height and diameter on a per tree basis via potential dimensional growth and competition. Based on the absolute cohort volume growth given by the physiological main model, the module uses the allometry to calculate the absolute height and diameter growth of each individual tree and the resulting new dimensions of the cohort representative. Both components are coupled within a feedback loop on annual timescale that keeps cohort layering and growth processes on one hand and individual tree stem- and crown dimensions on the other hand consistent with each other and prevents the module -states from drifting apart.

\section{Simulation setup and parameters}

Simulation runs with MoBiLE were conducted with the individual tree version (named MoBilE-ST in the following) and with the original version (MoBiLE alone). Tree initial diameters were available from measurements which had been taken in winter 1998/99 (Hauser 2003) and reflect the situation immediately after a thinning that had been applied before the definition of control plots. Initial height and crown dimensions were computed by SILVA. Three cohorts that were based on the diameter intervals (in $\mathrm{cm}$, end diameter excluded) 0-20, 20-30, 30- $\infty$ were defined on each site. As MoBiLE is generally designed to require sparse configuration, the individual tree module does not calculate the growth curve parameters $A, k$ and $p$ in Eq. 2 and the basal area growth modifier Esto via dose-response functions and additional site description. Instead, $A, k$, $p$ and Esto are directly given: within the scope of this study, their values refer to an average growth potential for southern Germany, following the idea, that the sole responsibility of the individual tree module is to control the relation of height to diameter growth and that it hence is sensitive to stand structure but robust with respect to site. A synopsis of the important parameters is given in Table 3 .

Weather data had been collected from 2001 to 2007 on a tower of approximately 1.5 times stand height within each of the sites and have been published in Holst et al. (2004a, 2010) as well as in Holst and Mayer (2005). Detailed descriptions of the instrumentation can be found in Mayer et al. (2002). The time interval of simulation was started from 2001 to end of 2007. A pre-run of 3 years preceded each simulation run to provide a plausible internal state of variables that cannot directly be initialized such as poolspecific nitrogen concentrations within the soil: they result from boundary conditions such as the total nitrogen concentration per layer and usually stabilize to realistic values within three simulated years. The stabilizing run was based on repetition of the weather of 2002 .

Five-year plot level results of MoBilE-ST and MoBiLE alone at NE-C and SW-C (2001-2005) were also compared with the ones of the stand-alone SILVA model. The observation-based model was initialized with the same tree lists and parameterized with the average of the same weather records.

The diameter growth to diameter distribution on the individual tree level as simulated by MoBiLE-ST was compared to the one that resulted from coring differentiated by plot, either as total growth of 2001-2005 or in selected years. As the tree diameters of the sample in the years of comparison were not directly measured, they were reconstructed from the tree ring analysis. Regressions between growth and DBH were done with the ordinary least squares algorithm (OLS), and prediction intervals were calculated from the residual variance.

Table 3 Growth curve parameters

\begin{tabular}{lll}
\hline Parameter & Value & Equation \\
\hline$A$ & 54 & Height growth $($ Chapman-Richards, \\
$k$ & 0.011 & Eq. 2): $h_{t}=A\left(1-e^{-k t}\right)^{p}$ \\
$p$ & 1.11 & \\
$\alpha$ & $1,327.8481$ & Diameter growth (Chapman-Richards 1st \\
$\kappa$ & 0.016363272 & derivative, Eq. 3): \\
$\varphi$ & 0.775173759 & $\delta_{d}=\alpha \kappa \varphi\left(1-e^{-\kappa d}\right)^{\varphi} e^{-\kappa d}$ \\
\hline
\end{tabular}


Fig. 6 General sample data properties: Mean year ring width by coring subsample of plot NE-C and plot SW-C. Ring widths directly after thinning are indicated by arrows. The measurements between 2001 and 2007 (test-set) served for further data analyses. Confidence interval of ring width is about $\pm 0.25 \mathrm{~mm}$

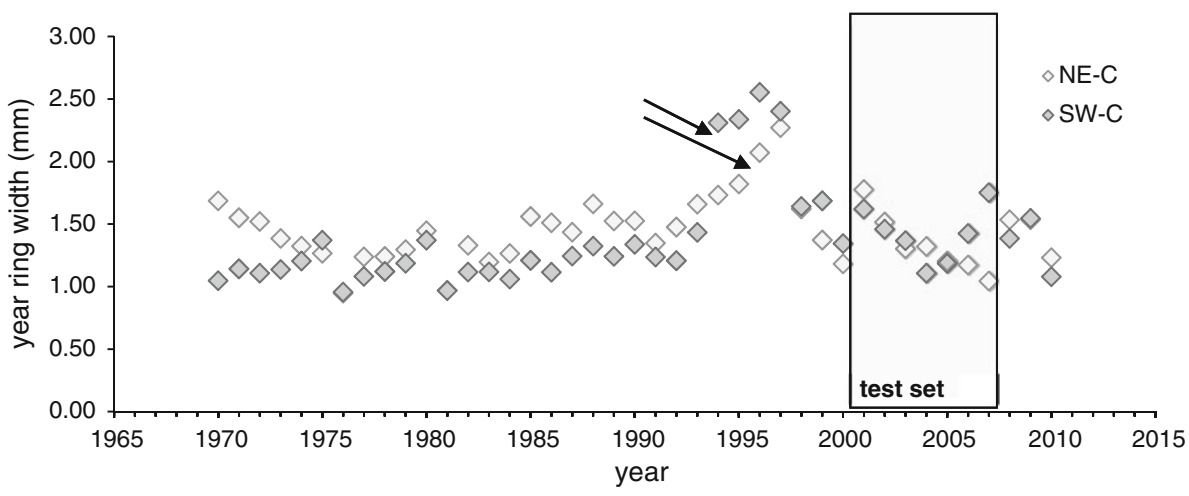

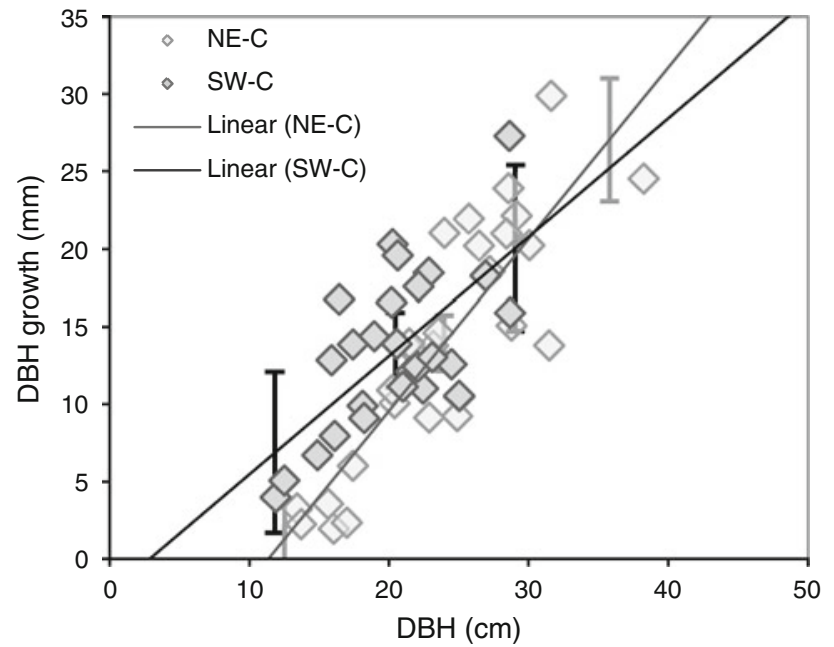

Fig. 7 General sample data properties: Diameter growth from 2001 to 2005 for each sample tree differentiated by site; the confidence band of the regression line is indicated by error bars $\left(R^{2}=0.74\right.$ at $\mathrm{NE}-\mathrm{C}, R^{2}=0.43$ at SW-C)

\section{Results}

Figures 6 and 7 show general properties of the sample data to give an impression of the plausibility and reliability of the dataset that was used for evaluation. In Fig. 6, the mean year ring width overtime from coring differentiated into plot NE-C and SW-C is presented. It shows a sharp decline in 1976, which was a year of severe drought. Growth peaks starting in 1994 at SW-C and 1996 at NE-C coincide with the last thinning before experimental site setup in 1999 (Hauser 2003). Within the time period of the simulation from 2001 to 2007, the year ring width displays a growth variation also typical for the period 1970-1994. From 2001 to 2005, NE-C and SW-C show a similar growth response with no particular incident in the dry year 2003. Figure 7 presents the distribution of DBH growth from 2001 to 2005 over $\mathrm{DBH}$ at both plots. It is equivalent to growth as dependent on tree size class and is one important evaluation criterion of the hybrid approach. The confidence band of diameter growth that is predicted by regression is indicated by error bars at mean DBH, at the estimated $2.5 \%$ quantile limit, and at $97.5 \%$-quantile limit of DBH. The data spread shows a usual variation of residuals at the individual tree level with $R^{2}=0.74$ at NE-C and $R^{2}=0.43$ at SW-C.

Figure 8 shows variability of tree growth as well as mean basal area stem growth of the coring subsample as compared to simulation results from MoBiLE without single-tree interpolation module (MoBiLE), MoBiLE with interpolation module (MoBiLE-ST) and SILVA from 2001 to 2005 differentiated by NE-C and SW-C. Error bars indicate confidence intervals of variability and growth here. MoBiLE alone underestimates measured growth in that five-year period from 2001 to 2005. It underestimates stand-scale variability at NE-C and overestimates it at SWC. MoBiLE-ST shows slight improvement with respect to mean basal area stem growth at NE-C and more realistic variability, which is somewhat underestimated at the site. At SW-C, the results are very close to measurement when the interpolation module is used. SILVA is close to the coring sample at NE-C, but at SW-C it overestimates local five-year growth and variability.

On the annual timescale (Fig. 9), the improvement of stand-level growth 2001-2007 that comes along with the use of the individual tree module is moderate at plot NE-C as well but remarkable at site SW-C. SILVA which is purely climate driven yields no additional information at that timescale. At plot NE-C, the deviation of mean over the 7 year timescale of 2001-2007 that is given as mean bias in mm was -0.59 with MoBiLE alone and -0.41 with MoBiLE-ST. At SW-C, the deviation strongly changed from -0.55 to -0.24 when MoBiLE-ST was used (confidence interval about \pm 0.8 ). As an indicator of quality on the annual timescale, the mean absolute bias decreased from 0.26 to 0.21 at NE-C and from 0.23 to 0.13 at SW-C when MoBiLE was used with the individual tree module (confidence interval about \pm 0.25 ).

Figure 10 shows measured and simulated individual tree DBH growth over DBH from 2001 to 2005 as well as in the 


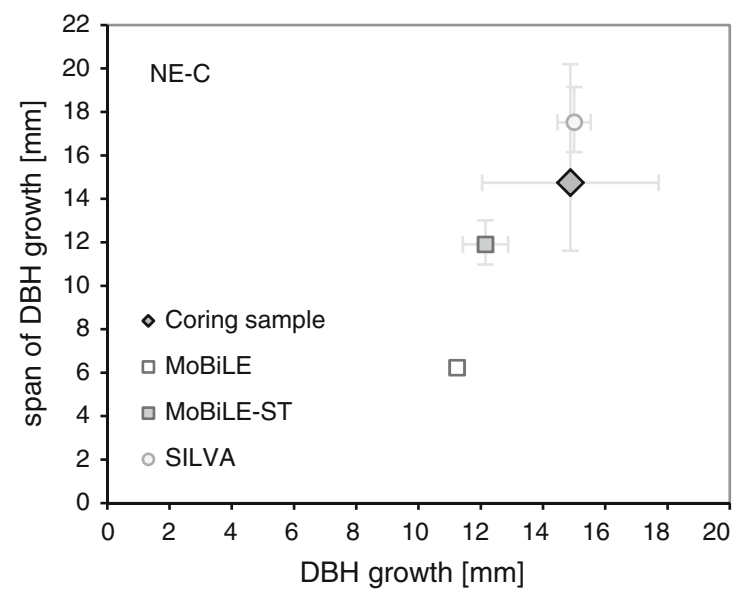

Fig. 8 Individual tree DBH growth 2001-2005 shown as plot level span of DBH growth over the mean basal area stem DBH growth at NE-C (left) and SW-C (right) differentiated by coring subsample,

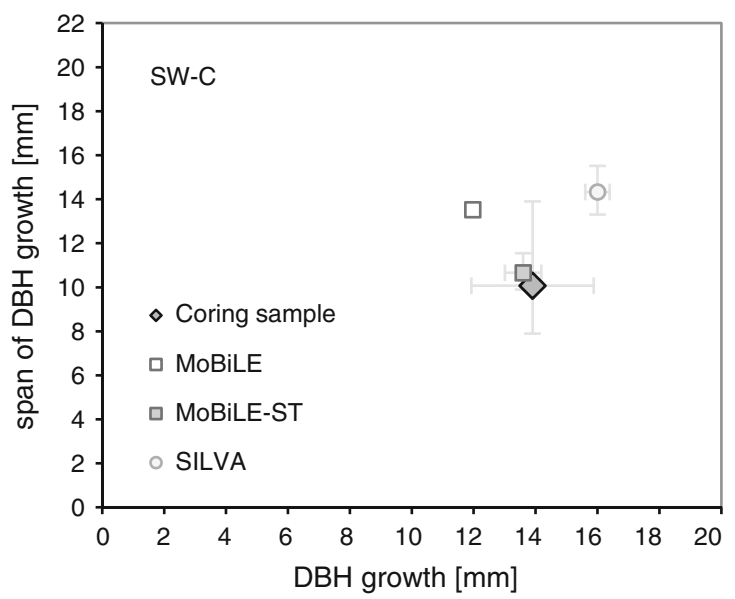

MoBiLE without interpolation module (MoBiLE), MoBiLE with interpolation module (MoBiLE-ST) and SILVA (error bars are confidence intervals here)
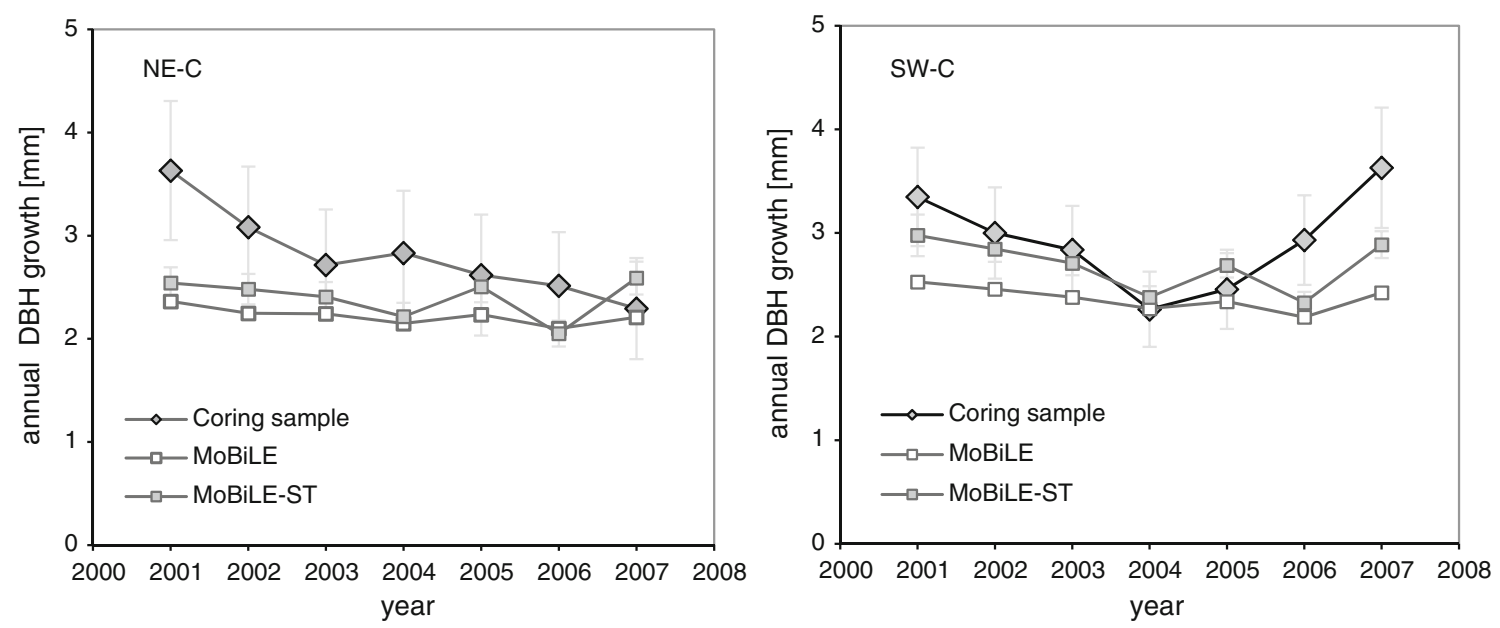

Fig. 9 Simulated and measured mean basal area stem DBH growth on plot NE-C and plot SW-C on annual timescale differentiated by MoBiLE without interpolation module (MoBiLE) and MoBiLE with interpolation module (MoBiLE-ST); confidence intervals are indicated by error bars

selected years 2001 and 2005 differentiated by trial plot: within the five-year range, the two individual years are marked by growth to size distributions and regressions of MoBiLE-ST that correspond to a large and a small standscale bias of growth, respectively, and limit the span of slope and data spread of the years with deviations lying in between. Cohort representative tree growth from MoBiLE alone is shown by one individual point per interval within the fiveyear growth to size distributions of NE-C and SW-C.

The confidence band of the simulated data regression does not exceed a growth span of about $1 \mathrm{~mm}$ at 5-year growth within the range of DBH variability given. Hence, the reliability of the comparisons shown in Fig. 10 is largely governed by the sample data confidence bands that may be taken from Fig. 7. The regression lines reflect a stronger underestimation of diameter growth by MoBiLE-
ST on the individual tree level as compared to stand-level aggregated growth in Figs. 8 and 9. MoBiLE-ST shows a more realistic distribution of diameter growth among the three cohorts than MoBiLE that overestimates growth in the lowest cohort as compared to the others. Within the two topmost cohorts, MoBiLE-ST shows a better estimation than MoBiLE alone that also underestimates there. In the lowest cohort, MoBiLE-ST underestimates and MoBiLE overestimates or estimates accurately (SW-C).

To give an impression how the model represents the distributional width of growth at the centre of the DBH distribution, the $95 \%$ prediction interval of growth at mean DBH is presented by error bars on the regression lines of simulation and measurement. The spread of individual tree diameter growth at site NE-C is met by the simulation results. In accordance with the measured distributional 

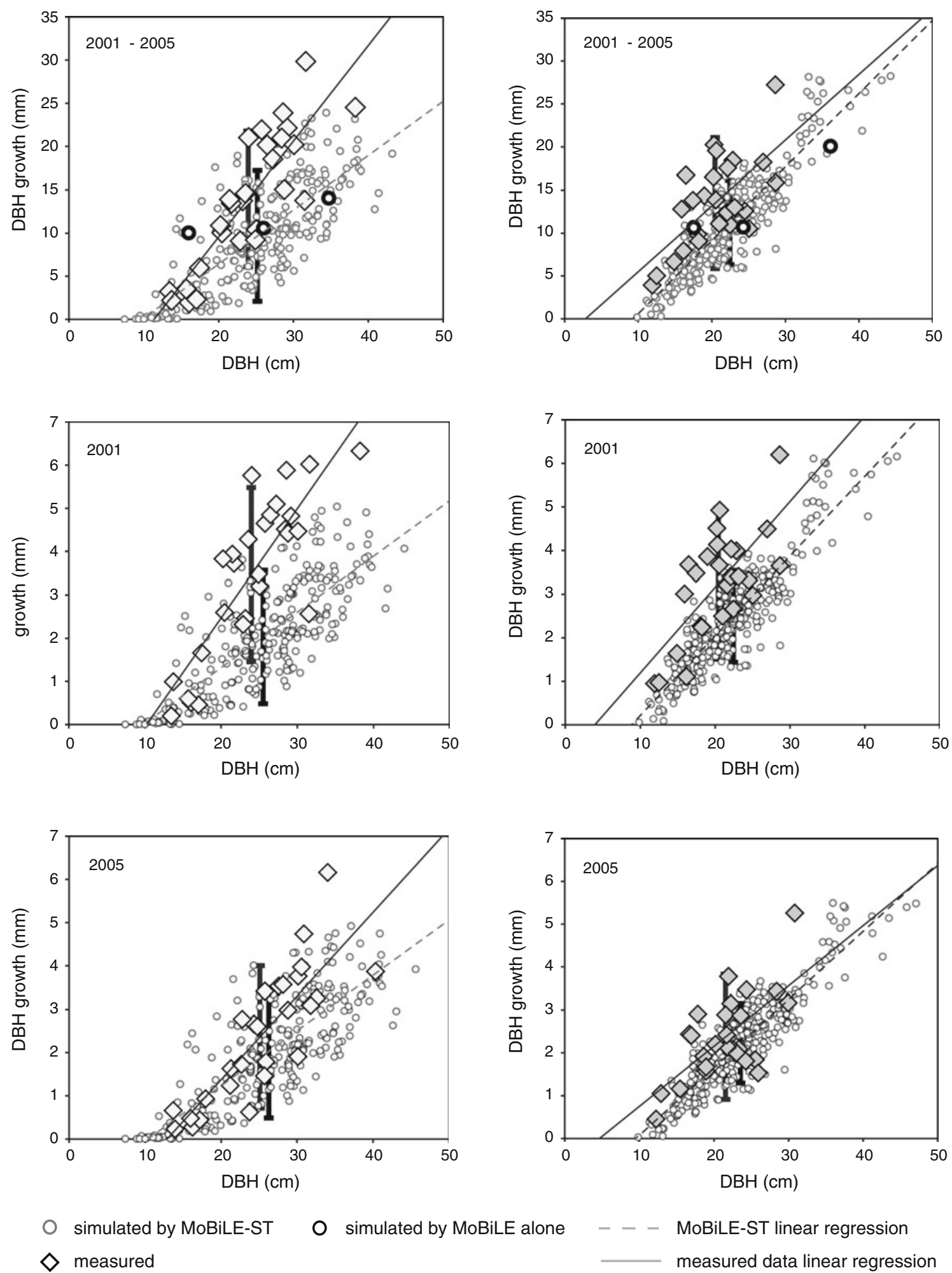

Fig. 10 Comparison of simulated and measured tree growth in the time range 2001-2005 (above), in 2001 (middle) and in 2005 (bottom); cohort intervals (in cm, end diameter excl.) at $0-20,20-30,30-\infty$; range of growth variation is indicated by bars (simulated black) 
width of diameters, simulated growth at SW-C is more narrow than at NE-C, albeit the absolute values are still underestimated.

\section{Discussion}

Generally, site quality is somewhat better at plot NE-C that has a larger basal area than the slightly older plot SW-C. Consistently, SW-C is more homogeneous in tree size and growth at this site is more equally distributed among trees. The year-to-year changes of average year ring width at both sites from 1970 to 2010 are often quite similar, including the significant drop in the very dry year 1976. In the mid of the 1990s, there are remarkable growth peaks at both sites. Interestingly, the SW-C plot showed inferior diameter growth than NE-C until this period but is growing similarly good or even better after this event. One plausible explanation for that shift is a mitigation of competition due to the last thinning before setup of the test sites in 1999. Another likely candidate to explain the observed change is that beech is relatively sensitive to drought (e.g. Friedrichs et al. 2009; Scharnweber et al. 2011) and precipitation might have increased at site SW: in contrast to the former statement about the sites that no significant differences appear across the valley (Geßler et al. 2001), measured precipitation at site SW-C from 2001 to 2007 was higher than at NE-C (1,027 compared to $865 \mathrm{~mm}$ annual average).

During the simulation period, the driest year was 2003 that has been shown to decrease carbon assimilation in Europe in general (Ciais et al. 2005) and for beech in particular (Charru et al. 2010). However, no growth depression in that year became obvious from the average year ring width of both plots. Similar results had been reported from other beech stands in Germany and the Netherlands (Mund et al. 2010; van der Werf et al. 2007), which were attributed to favourable growth conditions in early spring or after drought. It should also be noted that 2002 was the wettest year in the simulation period so that soil water storages were well filled.

Stand-scale results from all models were compared as growth over a five-year time period (the basic time step of SILVA), and simulations with MoBiLE-ST were compared to those of the original MoBiLE cohort model on an annual basis. During the time period from 2001 to 2005, simulations with SILVA correctly estimated average diameter growth at NE-C and overestimated it at SW-C, while the original MoBiLE version underestimated growth in both cases. With MoBiLE-ST, the results at NE-C were slightly better, and at $\mathrm{SW}-\mathrm{C}$, the representation of measured $\mathrm{DBH}$ growth considerably improved as compared to the original model.

On the individual tree level, MoBiLE-ST shows a more realistic relation between five-year diameter growth and tree diameter than MoBiLE alone, if the commonly used linear regression is applied to the result. It represents diameter growth in the two dominant cohorts better, albeit it underestimates growth in the lowest cohort. Both model versions would be more similar in total stand growth, if the cohorts were simply weighted by tree number. Even if the better representation of total stand growth by MoBiLE-ST notably at SW-C implies emphasis of dominant trees in averaging, it is also based on a more realistic diameter growth within the two upper cohorts and a better reflection of the size to growth relationship within the stand.

The gap in improvement between sites NE-C and SW-C might reflect the differences in stand structure between both sites: at NE-C, the topmost cohort is populated by more than 100 well-established dominant trees. Possibly, there is more investment into diameter and less into height within the dominant layer than it is predicted by the model, as trees are in a clearly dominant position and thus from a functional point of view might invest into leaf area and hence diameter rather than into height. In contrast, at SW$\mathrm{C}$, only about 40 dominant trees are established in the largest cohort, and these are concentrated within a circle of radius $20 \mathrm{~m}$ near the border of the plot. Here, the notable improvement of diameter growth within the upper two cohorts in MoBiLE-ST might be due to clustering of the most dominant group and hence lowered individual tree competition on the middle cohort.

In 2005 which is a year of good concordance between simulated and measured diameter growth on both sites, MoBiLE-ST accordingly showed a realistic slope and intercept of the diameter growth to diameter regression on the individual tree level. Whatsoever, it generally underestimated diameter increase as yet: one possible cause could be a deviation in the allometry of dominant trees at NE-C. Another is that volume growth both in MoBiLE-ST and MoBiLE is not sensitive to structural heterogeneity, as the physiological main model still perceives a cohort as horizontally homogeneous. Hence, improvements of diameter growth shown by MoBiLE-ST as compared to MoBiLE are exclusively due to a better description of allometry as yet, and one possible approach of further model optimization might be to correct the assumptions about canopy density in the light transmission of MoBiLE based on structural aspects like clustering.

At NE-C, the distributional width of simulated diameter growth at mean diameter was similar to the one of measured growth in the individual years 2001 and 2005 as well as over the time range 2001-2005. At site SW-C, the data spread of simulated growth was more narrow in accordance with the more homogeneous stand structure. However, it was smaller than the measured one in all cases which indicates that MoBiLE-ST could not capture the whole variability. On the other hand, the variation of year ring 
width might have been artificially increased due to general measurement uncertainties, particularly related to diffuse porous wood. However, simulated residual variability of annual growth did not exceed the one of the coring sample in any of the cases.

One of the key challenges for the physiological model is the age dependence of parameters and processes, e.g. with respect to water supply, stomatal conductance and assimilation (Magnani et al. 2008; Delzon et al. 2004) that is relevant in particular for simulations of uneven-aged stands or over rotations. Therefore, one of the major tasks of future research and development is the investigation of the tree size dependence of water stress and the according further refinement of the physiological model part. The focus of this study is on the dependence of allometry on biological age and competition that is delegated to an observation-based module. As a matter of model simplicity, the approach as yet implies that allometry at a given stand structure was site independent within a large ecoregion. A further step of development might be to add doseresponse functions of growth potential taken from SILVA and to extend the model preferences by site information: To increase the site dependence of height growth to diameter growth on one hand could improve the results on the short time range that have been presented in this study. On the other hand, although the physiological main model and the individual tree component are coupled in a feedback loop to prevent from module drift, a higher spatial resolution of allometry might be beneficial to mitigate a possible bias between modelled and real individual tree dimension over a rotation. The approach used so far aims to save costs of model maintenance and parameterization. As the dose-response functions of SILVA were parameterized on the stand-scale level, the investment into a more stand-related allometry might pay off.

Our results indicate that the average stand development indeed depends on individual tree size distribution and that the incorporation of individual tree competition into MoBiLE improves the representation of environmental influences in long-term simulations of forest development. The added value of the hybrid model in comparison with the SILVA growth simulator is the consideration of interannual variability: MoBiLE-ST is not necessarily more accurate in the prediction of growth considering current climate conditions, but it is sensitive to a change in the inter-annual as well as intra-annual weather regime and hence adds understanding about the long-term effect of a changing climate on competition and structural dynamics. The coupling of an individual tree module into MoBiLE follows a well-justified demand for hybrid models that combine physiological responses with observation-based stand structure development (Mäkelä et al. 2000). Earlier coupling approaches used either a unidirectional linkage between physiological- and observation-based module (Henning and Burk 2004) or bidirectional linkages with large (several years) time steps before considering structural feedbacks (Milner et al. 2003). Also, dimensional change was eventually not consistently related to biomass growth (Baldwin et al. 2001). Weiskittel et al. (2010), Kirschbaum (1999) and Korol et al. (1996) have addressed the issue of mass conservative stand NPP distribution by a weight that was related to the estimated proportion of light acquired by a tree's crown. Dimension growth was calculated via allometric equations from the individual tree volume. As underlined by Watt and Kirschbaum (2011), allometry is not only age dependent but also related to site factors that are at least to a part related to competition, such as stand density. Hence, our approach within the same interpolation step (1) pre-estimates individual tree growth with a distance-dependent observation-based model to provide competition-dependent allometry as well as to scale down cohort volume growth to an individual tree volume change and then (2) corrects the pre-estimated individual tree dimension growth to suffice the individual tree relative volume increase. It aims to minimize the investment into site-specific calibration and to achieve generality with respect to species composition and age class. The specific advantage of the presented coupling is a clear division of tasks between physiological carbon allocation and observation-based allometry: on one hand, the physiological main model is highly sensitive to environmental variability but would be expensive to parameterize and slow on the individual tree level. Therefore, it uses the concept of a cohort model. On the other hand, the observation-based individual tree module is more straightforward and much faster in simulating individual tree growth. It is less sensitive to site conditions. Hence, it exclusively centres upon the ratio of growth in height and diameter, i.e. allometry. The approach combines the major advantages of both model types. Furthermore, it all in one (1) utilizes a mass conservative algorithm to convert stand carbon allocation to individual tree dimensional change, (2) has a bidirectional coupling of cohort mass and volume growth on one hand and of individual tree allometry on the other at the annual timescale, (3) implies a feedback loop to prevent cohort carbon allocation and individual tree dimensional change from drifting apart and (4) utilizes a fast allometry algorithm from a tried and tested observation-based model to extend a physiological model.

Similar to what we propose here, Kimmins et al. (1999) addressed hybridization with the FORCAST model by predefining the time course of stem size distribution at simulation start. The rates of growth of all trees are computed relative to the median tree. Our approach, however, extends this concept, in that it includes the distribution of tree dimension as an intrinsic variable that dynamically 
evolves from the initial size and position of the stand's trees, the growth of the stand cohorts and the competition within the stand. Therefore, the approach is well suited to address some interesting questions in the future. For example, whether management can mitigate increasing drought stress by reducing the competition on water (Kohler et al. 2010), or to what degree the relation between aboveground and belowground competition processes might change under changing environmental conditions (Pretzsch and Biber 2010; Pretzsch and Dieler 2011).

\section{Conclusion}

Inclusion of an individual tree module (taken from SILVA) into a physiological model (MoBiLE-PSIM) improved the spatial representation of competition and growth on 5 year and even annual timescale. This is particularly the case where the spatial distribution of dominant trees is clustered. Still, there might be room for model improvement in a more detailed relation between crown dominance and development of the height to diameter ratio. In a year where the accuracy of stand growth simulation is high, also mean growth at given tree size is well represented. The competition module might require further improvement in reproducing the distributional width in structurally homogeneous stands. Further investigations would be needed to assert that the model reflects the relation between tree dominance and competitive advantage also in years of extremely low soil resource supply.

Acknowledgments Funding of this work by the German Science Foundation/Deutsche Forschungsgemeinschaft (DFG) within the Project 'Modelling beech-dominated deciduous forest development based on competitive mechanisms of water and nitrogen partitioning, under contract number GE 1090/9-1 is greatly acknowledged. Furthermore, we thank Matthias Ulbricht and Gerhard Schütze for their thorough sampling of tree cores and careful measurement of growth rings, without which this investigation would not have been possible.

Open Access This article is distributed under the terms of the Creative Commons Attribution License which permits any use, distribution, and reproduction in any medium, provided the original author(s) and the source are credited.

\section{References}

Baldwin VC Jr, Burkhart HE, Westfall JA, Peterson KD (2001) Linking growth and yield and process models to estimate impact of environmental changes on growth of loblolly pine. Forest Sci 47:77-82

Ball JT, Woodrow IE, Berry JA (1987) A model predicting stomatal conductance and its contribution to the control of photosynthesis under different environmental conditions. In: Biggins J (ed)
Progress in photosynthesis research. Martinus-Nijhoff Publishers, Dordrecht, pp 221-224

Boisvenue C, Running SW (2006) Impacts of climate change on natural forest productivity-evidence since the middle of the 20th century. Global Change Biol 12:862-882

Bolte A, Czajkowski T, Kompa T (2007) The north-eastern distribution range of European beech-a review. Forestry 80:413-429

Bolte A, Hilbrig L, Grundmann B, Kampf F, Brunet J, Roloff A (2010) Climate change impacts on stand structure and competitive interactions in a southern Swedish spruce-beech forest. Eur J Forest Res 129:261-276

Brumme R, Khanna PK (2009) Stand, soil and nutrient factors determining the functioning and management of beech forest ecosystems: a synopsis. In: Brumme R, Khanna PK (eds) Functioning and management of european beech ecosystems. Springer, Berlin-Heidelberg, pp 459-491

Charru M, Seynave I, Morneau F, Bontemps JD (2010) Recent changes in forest productivity: an analysis of national forest inventory data for common beech (Fagus sylvatica L.) in northeastern France. For Ecol Manage 260:864-874

Ciais Ph, Reichstein M, Viovy N, Granier A, Ogee J, Allard V, Aubinet M, Buchmann N, Bernhofer C, Carrara A, Chevallier F, De Noblet $N$, Friend $A D$, Friedlingstein $P$, Grünwald $T$, Heinesch B, Keronen P, Knohl A, Krinner G, Loustau D, Manca G, Matteucci G, Miglietta F, Ourcival JM, Papale D, Pilegaard K, Rambal S, Seufert G, Soussana JF, Sanz MJ, Schulze ED, Vesala T, Valentini R (2005) Europe-wide reduction in primary productivity caused by the heat and drought in 2003. Nature 437:529-533

Delzon S, Sartore M, Burlett R, Dewar R, Loustau D (2004) Hydraulic responses to height growth in maritime pine trees. Plant Cell Environ 27(9):1077-1087

Farquhar GD, Von Caemmerer S, Berry JA (1980) A biochemical model of photosynthetic $\mathrm{CO}_{2}$ assimilation in leaves of $\mathrm{C}_{3}$ species. Planta 149:78-90

Fontes L, Bontemps J-D, Bugmann H, Van Oijen M, Gracia C, Kramer K, Lindner M, Rötzer T, Skovsgaard JP (2010) Models for supporting forest management in a changing environment. For Syst 19:8-29

Friedrichs D, Trouet V, Büntgen U, Frank D, Esper J, Neuwirth B, Löffler J (2009) Species-specific climate sensitivity of tree growth in Central-West Germany. Trees 23:729-739

Geßler A, Schrempp S, Matzarakis A, Mayer H, Rennenberg H (2001) Radiation modifies the effect of water availability on the carbon isotope composition of beech (Fagus sylvatica). New Phytol 150:653-664

Geßler A, Jung K, Gasche R, Papen H, Heidenfelder A, Börner E, Metzler B, Augustin S, Hildebrand E, Rennenberg H (2005) Climate and forest management influence nitrogen balance of European beech forests: microbial $\mathrm{N}$ transformations and inorganic $\mathrm{N}$ net uptake capacity of mycorrhizal roots. Eur $\mathbf{J}$ For Res 124:95-111

Geßler A, Keitel C, Kreuzwieser J, Matyssek R, Seiler W, Rennenberg $\mathrm{H}$ (2007) Potential risks for European beech (Fagus sylvatica $\mathrm{L}$.) in a changing climate. Trees 21:1-11

Goreaud F, Alvarez I, Courbaud B, de Coligny F (2006) Long-term influence of the spatial structure of an initial state on the dynamics of a forest growth model: a simulation study using the Capsis platform. Simulation 82:475-495

Grote R (1998) Integrating dynamic morphological properties into forest growth modeling. II. Allocation and mortality. For Ecol Manage 111:193-210

Grote R (2007) Sensitivity of volatile monoterpene emission to changes in canopy structure-a model based exercise with a process-based emission model. New Phytol 173:550-561 
Grote R, Pretzsch H (2002) A model for individual tree development based on physiological processes. Plant Biol (Stutt) 4:167-180

Grote R, Lehmann E, Brümmer C, Brüggemann N, Szarzynski J, Kunstmann H (2009) Modelling and observation of biosphereatmosphere interactions in natural savannah in Burkina Faso, West Africa. Phys Chem Earth 34:251-260

Grote R, Kiese R, Grünwald T, Ourcival J-M, Granier A (2011a) Modelling forest carbon balances considering tree mortality and removal. Agric For Meteorol 151:179-190

Grote R, Korhonen J, Mammarella I (2011b) Challenges for evaluating process-based models of gas exchange at forest sites with fetches of various species. For Syst 20(3):389-406

Hauser S (2003) Dynamik hochaufgelöster radialer Schaftveränderungen und des Dickenwachstums bei Buchen (Fagus sylvatica L.) der Schwäbischen Alb unter dem Einfluss von Witterung und Bewirtschaftung. Freiburg i. Brsg., Albert-Ludwigs-Universität Freiburg i. Brsg. pp 212

Henning JG, Burk TE (2004) Improving growth and yield estimates with a process model derived growth index. Can J For Res 34:1274-1282

Holst T, Mayer H (2005) Radiation components of beech stands in Southwest Germany. Meteorol Zeitschrift 14:107-115

Holst T, Hauser S, Kirchgäßner A, Matzarakis A, Mayer H, Schindler D (2004a) Measuring and modelling plant area index in beech stands. Int J Biometeorol 48:192-201

Holst T, Mayer H, Schindler D (2004b) Microclimate within beech stands-part II: thermal conditions. Eur J Forest Res 123:13-28

Holst J, Grote R, Offermann C, Ferrio JP, Gessler A, Mayer H, Rennenberg H (2010) Water fluxes within beech stands in complex terrain. Int J Biometeorol 54:23-36

Jump AS, Hunt JM, Peñuelas J (2006) Rapid climate change-related growth decline at the southern range edge of Fagus sylvatica. Global Change Biol 12:2163-2174

Kimmins JP, Mailly D, Seely B (1999) Modelling forest ecosystem net primary production: the hybrid simulation approach used in FORECAST. Ecol Modell 122:195-224

Kirschbaum MUF (1999) CenW, a forest growth model with linked carbon, energy, nutrient and water cycles. Ecol Modell 118:17-59

Koca D, Smith B, Sykes MT (2006) Modelling regional climate change effects on potential natural ecosystems in Sweden. Clim Chang 78:381-406

Kohler M, Sohn J, Nägele G, Bauhus J (2010) Can drought tolerance of Norway spruce (Picea abies (L.) Karst.) be increased through thinning? Eur J For Res 129:1109-1118

Korol RL, Milner KS, Running SW (1996) Testing a mechanistic model for predicting stand and tree growth. For Sci 42:139-153

Kubiske ME, Quinn VS, Heilman WE, McDonald EP, Marquardt PE, Teclaw RM, Friend AL, Karnosky DF (2006) Interannual climatic variation mediates elevated $\mathrm{CO}_{2}$ and $\mathrm{O}_{3}$ effects on forest growth. Global Chang Biol 12:1054-1068

Landsberg J (2003) Physiology in forest models: history and the future. FBMIS 1:49-63

Langvall O, Löfvenius MO (2002) Effect of shelterwood density on nocturnal near-ground temperature, frost injury risk and budburst date of Norway spruce. For Ecol Manage 168:149-161

Li C, Frolking S, Frolking TA (1992) A model of nitrous oxide evolution from soil driven by rainfall events: 1 . Model structure and sensitivity. J Geophys Res 97:9759-9776

Löw M, Herbinger K, Nunn AJ, Häberle K-H, Leuchner M, Heerdt C, Werner H, Wipfler P, Pretzsch H, Tausz M, Matyssek R (2006) Extraordinary drought of 2003 overrules ozone impact on adult beech trees (Fagus sylvatica). Trees 20:539-548

Maaten E (2011) Climate sensitivity of radial growth in European beech (Fagus sylvatica L.) at different aspects in southwestern Germany. Trees 26:777-788
Magnani F, Bensada A, Cinnirella S, Ripullone F, Borghetti M (2008) Hydraulic limitations and water-use efficiency in Pinus pinaster along a chronosequence. Can J For Res 38(1):73-81

Mäkelä A, Landsberg J, Ek AR, Burk TE, Ter-Mikaelian M, Ågren GI, Oliver CD, Puttonen P (2000) Process-based models for forest ecosystem management: current state of the art and challenges for practical implementation. Tree Physiol 20:289-298

Martin GL, Ek AR, Monserud RA (1977) Control of plot edge bias in forest stand growth simulation models. Can J For Res 7(1):100-105

Matyssek R, Le Thiec D, Löw M, Dizengremel P, Nunn AJ, Häberle $\mathrm{KH}$ (2006) Interactions between drought and $\mathrm{O}_{3}$ stress in forest trees. Plant biol 8:11-17

Mayer H, Holst T, Schindler D (2002) Microclimate within beech stands-part I: photosynthetically active radiation. Forstw Cbl 121:301-321

Milner KS, Coble DW, McMahan AJ, Smith EL (2003) FVSBGC: a hybrid of the physiological model STAND-BGC and the forest vegetation simulator. Can J For Res 33:476-479

Mund M, Kutsch WL, Wirth C, Kahl T, Knohl A, Skomarkova MV, Schulze E-D (2010) The influence of climate and fructification on the inter-annual variability of stem growth and net primary productivity in an old-growth, mixed beech forest. Tree Physiol 30(6):689-704

Muys B, Hynynen J, Palahí M, Lexer MJ, Fabrika M, Pretzsch H, Gillet F, Briceño E, Nabuurs G-J, Kint V (2010) Simulation tools for decision support to adaptive forest management in Europe. For Syst 19:86-99

Ollinger SV, Aber JD, Reich PB, Freuder RJ (2002) Interactive effects of nitrogen deposition, tropospheric ozone, elevated $\mathrm{CO}_{2}$ and land use history on the carbon dynamics of northern hardwood forests. Global Chang Biol 8:545-562

Paul T (2003) Die Vegetation in Kalkbuchenwäldern in Abhängigkeit von Standort und forstlicher Nutzung. Albert-Ludwigs-Universität, Freiburg in Breisgau $257 \mathrm{pp}$

Porte' A, Bartelink HH (2002) Modelling mixed forest growth: a review of models for forest management. Ecol Modell 150:141-188

Portsmuth A, Niinemets Ü (2007) Structural and physiological plasticity in response to light and nutrients in five temperate deciduous woody species of contrasting shade tolerance. Funct Ecol 21:61-77

Pretzsch H, Biber P (2010) Size-symmetric versus size-asymmetric competition and growth partitioning among trees in forest stands along an ecological gradient in central Europe. Can J For Res 40:370-384

Pretzsch H, Dieler J (2011) The dependency of the size-growth relationship of Norway spruce (Picea abies [L.] Karst.) and European beech (Fagus sylvatica [L.]) in forest stands on longterm site conditions, drought events, and ozone stress. Trees 25:355-364

Pretzsch H, Biber P, Dursky J (2002) The single tree-based stand simulator SILVA: construction, application and evaluation. For Ecol Manage 162:3-21

Pretzsch H, Grote R, Reineking B, Rötzer T, Seifert S (2008) Models for forest ecosystem management: a European perspective. Ann Bot 101:1065-1087

Richards FJ (1959) A flexible growth function for empirical use. J Exp Bot 10:290-300

Rötzer T, Grote R, Pretzsch H (2005) Effects of environmental changes on the vitality of forest stands. Eur J For Res 124:349-362

Saxe H, Cannell MGR, Johnsen O, Ryan MG, Vourlitis G (2002) Tree and forest functioning in response to global warming. New Phytol 149:369-399 
Scharnweber T, Manthey M, Criegee C, Bauwe A, Schröder C, Wilmking M (2011) Drought matters-declining precipitation influences growth of Fagus sylvatica L. and Quercus robur L. in north-eastern Germany. For Ecol Manage 262:947-961

Schwinning S, Weiner J (1998) Mechanisms determining the degree of size asymmetry in competition among plants. Oecologia 113:447-455

van der Werf GW, Sass-Klaassen UGW, Mohren GMJ (2007) The impact of the 2003 summer drought on the intra-annual growth pattern of beech (Fagus sylvatica L.) and oak (Quercus robur L.) on a dry site in the Netherlands. Dendrochronologia 25:103-112

Watt MS, Kirschbaum MUF (2011) Moving beyond simple linear allometric relationships between tree height and diameter. Ecol Modell 222:3910-3916
Weiner J (1990) Asymmetric competition in plant populations. Trends Ecol Evol 5:360-364

Weiskittel A, Maguire D, Monserud R, Johnson G (2010) A hybrid model for intensively managed Douglas-fir plantations in the Pacific Northwest, USA. Eur J For Res 129:325-338

Wichmann L (2001) Annual variations in competition symmetry in even-aged Sitka spruce. Ann Bot 88:145-151

Wichmann L (2002) Modelling the effects of competition between individual trees in forest stands. Royal Veterinary and Agricultural University, Copenhagen 